\title{
Polymorphism in the flanking regions of the PbGP43 gene from the human pathogen Paracoccidioides brasiliensis: search for protein binding sequences and poly $(A)$ cleavage sites
} Antonio A Rocha1, Flávia V Morais ${ }^{2}$ and Rosana Puccia*1

Address: ${ }^{1}$ Department of Microbiology, Immunology and Parasitology, Federal University of São Paulo (UNIFESP), 04023-062 São Paulo, SP, Brazil and 2Laboratory of Molecular Genetics and Genomics, University of Vale do Paraíba (UNIVAP), SP, Brazil

Email: Antonio A Rocha - rocha14@unifesp.br; Flávia V Morais - moraisfv@hotmail.com; Rosana Puccia* - rpuccia@unifesp.br

* Corresponding author

Published: 30 December 2009

BMC Microbiology 2009, 9:277 doi:10.1 I86/I47|-2180-9-277
Received: 23 June 2009

Accepted: 30 December 2009

This article is available from: http://www.biomedcentral.com/I47I-2/80/9/277

(C) 2009 Rocha et al; licensee BioMed Central Ltd.

This is an Open Access article distributed under the terms of the Creative Commons Attribution License (http://creativecommons.org/licenses/by/2.0), which permits unrestricted use, distribution, and reproduction in any medium, provided the original work is properly cited.

\begin{abstract}
Background: Paracoccidioides brasiliensis is a thermo-dimorphic fungus that causes paracoccidiodomycosis (PCM). Glycoprotein gP43 is the fungal main diagnostic antigen, which can also protect against murine PCM and interact with extracellular matrix proteins. It is structurally related to glucanases, however not active, and whose expression varies considerably. We have presently studied polymorphisms in the PbGP43 flanking regions to help understand such variations.

Results: we tested the protein-binding capacity of oligonucleotides covering the PbGP43 proximal 5 ' flanking region, including overlap and mutated probes. We used electrophoretic mobility shift assays and found DNA binding regions between positions -134 to -103 and -255 to -215 . Only mutation at -230 , characteristic of $P$. brasiliensis phylogenetic species PS2, altered binding affinity. Next, we cloned and sequenced the $5^{\prime}$ intergenic region up to position $-2,047$ from $P$. brasiliensis $\mathrm{Pb} 339$ and observed that it is composed of three tandem repetitive regions of about $500 \mathrm{bp}$ preceded upstream by $442 \mathrm{bp}$. Correspondent PCR fragments of about 2,000 bp were found in eight out of fourteen isolates; in PS2 samples they were 1,500-bp long due to the absence of one repetitive region, as detected in Pb3. We also compared fifty-six PbGP43 3' UTR sequences from ten isolates and have not observed polymorphisms; however we detected two main poly(A) clusters $(I, 420$ to $I, 44 I$ and I,45I to I,457) of multiple cleavage sites. In a single isolate we found one to seven sites.

Conclusions: We observed that the amount of PbGP43 transcripts accumulated in $P$. brasiliensis $\mathrm{Pb} 339$ grown in defined medium was about 1,000 -fold higher than in $\mathrm{Pb} / 8$ and 120 -fold higher than in $\mathrm{Pb} 3$. We have described a series of features in the gene flanking regions and differences among isolates, including DNA-binding sequences, which might impact gene regulation. Little is known about regulatory sequences in thermo-dimorphic fungi. The peculiar structure of tandem repetitive fragments in the $5^{\prime}$ intergenic region of $\mathrm{PbGP43}$, their characteristic sequences, besides the presence of multiple poly (A) cleavage sites in the 3' UTR will certainly guide future studies.
\end{abstract}




\section{Background}

Paracoccidioides brasiliensis is a thermo-dimorphic pathogenic fungus. It causes paracoccidiodomycosis (PCM) in man, which is an endemic mycosis in Latin America that affects mostly the lungs, but can disseminate to other organs [1]. P. brasiliensis is multinucleated in both pathogenic yeast and infectious mycelial phases. Genetic transformation in the species has recently been optimized [2], however genetic manipulation is still in its infancy. It is now recognized that most $P$. brasiliensis isolates diversified into an S1 main species, which is genetically close to the PS3 group of Colombian isolates, while PS2 is composed of a few isolates that constitute a phylogenetically cryptic species [3].

Gp43 is the main diagnostic and prognostic antigen so far characterized in $P$. brasiliensis $[4,5]$. It is a secretory glycoprotein whose peptide structure bears antigenic properties that are peculiar to the species [6]. Therefore, it confers high levels of sensitivity and specificity for PCM patients' sera when used as antigen in diagnostic tests such as immunodiffusion and capture ELISA, as well as by antigen detection in biological fluids [7]. Antibody titers are directly proportional to the severity of active PCM; they are probably not protective in advanced stages of the disease, but experimental protocols in mice point to the immunotherapeutic potential of anti-gp43 monoclonal antibodies [8]. On the other hand, gp43 contains T cell epitopes that are protective to vaccinated mice [5]. The best studied T-cell epitope is 15 aminoacid-long P-10, which showed additive effect in the treatment of murine PCM when administered with anti-fungal agents [9]. In addition, gp43 has adhesive properties to extracellular matrix proteins that may help fungal dissemination $[10,11]$.

The complete PbGP43 ORF has originally been found in a cloned 3,800-bp EcoRI genomic region from the Pb339 (B-339) isolate. It comprises 1,329 bp that contain a unique 78-bp intron [12]. The EcoRI genomic fragment includes $326 \mathrm{bp}$ from the PbGP43 5 ' intergenic proximal region and about 500 bp of the $3^{\prime}$ intergenic sequence, which is shared by a neighboring RanBP homologue. This gene encodes a nuclear Ran-binding protein in Schizosaccharomyces pombe, or importin 11 in Aspergillus fumigatus, that transports ribosomal proteins to the nucleus [13]. PbGP43 and $\mathrm{PbRanBP}$ are linked in twelve P. brasiliensis isolates, as observed by Feitosa et al. [14].

Our group has carried out original and detailed studies on sequence polymorphism in the PbGP43 ORF [15] and 5' intergenic proximal region [16], which defined at least five genotypes [17]. When compared to a consensus sequence, the most polymorphic A genotype carries three substitutions in the 5 ' intergenic proximal region and up to fifteen informative sites in the ORF, mostly concen- trated in exon 2. So far, the A genotype has been detected in all six PS2 isolates [3]. It is of note that PbGP43 was the most polymorphic gene in the multilocus analysis performed by Matute et al. [3] in P. brasiliensis. Isolates Pb2, Pb3 and Pb4, which belong in PS2 group [3], evoked milder experimental PCM in B10. A mice than representative isolates from the main species $\mathrm{S} 1$, including $\mathrm{Pb} 18$ [16]. This isolate has been long used in experimental PCM due to its high virulence.

P. brasiliensis $\mathrm{Pb} 339$ has traditionally been employed in antigen preparation [18]. It secretes high amounts of gp43, however that is not a rule among isolates [19]. The amount of gp43 accumulated in the extracellular fluids of a single isolate also varies with incubation time, culture medium, fungal phase, as well as with multiple sub-culturing after animal passage. In yeast-phase Pb339, extracellular gp43 decreases through late-log and stationary phases $[18,20]$, when the culture $\mathrm{pH}$ tends to be basic [21]. Expression regulation of gp43 is only beginning to be unrevealed. Previous data from our group suggested that PbGP43 suffers transcriptional regulation, but we showed that modulation at protein and secretion levels might also happen [16]. Besides, transcriptional response of $\mathrm{Pb} 3$ isolate to heat shock differed from others belonging to $P$. brasiliensis $\mathrm{S} 1$ group, suggesting that differences in PbGP43 transcriptional regulation are likely to occur among isolates [16]. On the other hand, we have recently mapped NIT2-like binding motifs in the PbGP43 5' intergenic region and described transcription modulation with nitrogen primary sources. In that case, the degree of modulation was similar among different isolates [22].

Differences in gp43 expression could be related to differences in transcription regulation due to genetic polymorphisms in the PbGP43 flanking regions. In the present work, we found protein binding sequences in the proximal PbGP43 5' flanking fragment and studied the effect of substitution sites; we characterized an extended 5' intergenic region up to $2,047 \mathrm{bp}$ from $\mathrm{Pb} 339$ in comparison with other isolates and recognized some peculiar sequence organization. In addition, we studied polymorphism in the 3' UTR and polyadenylation cleavage site of the PbGP43 transcript. Accumulation of PbGP43 transcripts was much higher in Pb339 than in Pb18 and Pb3, however they were similarly modulated with glucose. The differences we presently found in the Pb339 5' intergenic region might help understand the features involved in differences of PbGP43 transcriptional regulation.

\section{Results \\ Search for DNA binding regions in the proximal PbGP43 5' flanking region}

In order to find protein binding sites within the proximal 5' flanking region of the PbGP43 gene cloned by Cisalpino et al. [12] we carried out EMSA using total protein 
extracts of $P$. brasiliensis and selected oligonucleotides (Table 1). Selection was based on the search for transcription factors using the TFSearch program (Figure 1) and DNAse I protection footprinting assays (data not shown), as established in our previous works $[22,23]$. We were aware of the incomplete type of information that transcription factor search programs could provide; however that was the strategy of choice to start our analysis. We were particularly interested to find DNA binding sequences in polymorphic regions.

The first set of probes tested by EMSA included Bs2, Bs8.1, Bs8.1 $\Delta$, Bs8.2 $\Delta$ and Bs10 (Figure 1, Table 1). Bs2 and Bs 10 resulted negative (data not shown), while the overlapping

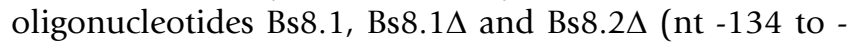
103) formed intense shifted bands that were specifically inhibited with 100-fold excess of cold homologous probes, suggesting specificity (Figure 2A). Oligonucleotides Bs8.1 $\Delta$ and Bs8.2 $\Delta$ (nt -134 to -113 ) included substitutions at positions -120 (T/A) and/or $-104(\mathrm{C} / \mathrm{G})$ that are characteristic of $P$. brasiliensis isolates belonging to phylogenetic species PS2, which is presently represented by $\mathrm{Pb} 3[3,15]$. However, these substitutions did not seem to alter the intensity of protein binding (Figure 2A). In addition, probes Bs8.1, Bs8.1 $\Delta$ and Bs8.2 $\Delta$ cross-competed (Figure 2B). The Bs8.1, Bs8.1 $\Delta$ and Bs8.2 $\Delta$ complexes migrated similarly and the probes are similar in size (22 and 24 mer), suggesting binding to the same protein. Therefore, our results point to a protein binding core in the overlapping sequence TGCAGAA/TTTATCAA. Alternatively, all the probes are competing for distinct Sox-5like protein binding sites (Figure 1). It is necessary to point out, however, that all the interpretations drawn from EMSA using total protein extracts will only possibly be confirmed by using either purified transcription factors or specific antibodies in super-shift experiments, considering that differences in shifts could be evoked by the same protein, while similar migrations could alternatively be the result of different transcription factors.

The next set of probes tested by EMSA included Et12, Et23, Et23 $\Delta$, Et4 and Et5 (Figure 1, Table 1). We tested

Table I: Sense oligonucleotides used in EMSA reactions

\begin{tabular}{cl}
\hline Et 12 & 5' CCC TGG CAT CTG CTG TTG ATC TTT T 3' \\
Et23 & 5' CTG TTG ATC TTT TCC TTA TTT TGT GGA 3' \\
Et23 & 5' CTG TTG ATC TTT TAC TTA TTT TGT GGA 3' \\
Et4 & 5' GCT ATC ACC TGT GGA CTC 3' \\
Et5 & 5' TTA AAG CTC ACT TGG ACC ATT 3' \\
Et6 & 5' GGG ATT ATG GTG TAT AAA TA 3' \\
Et7 & 5' AAG GGC CTG GTG TGA TTC TC 3' \\
Bs2 & 5' TTC TCA TGT TAC AGC A 3' \\
Bs8.1 $\Delta$ & 5' TGC AGA ATT ATC AAC AAT TAT GGA 3' \\
Bs8.I & 5' TGC AGA TTT ATC AAC AAT TAT GCA 3' \\
Bs8.2 & 5' TTC ATT GTT GCA GAA TTA TCA A 3' \\
Bs 10 & 5' TGT ATA AAT ATC TGC TGT 3' \\
\hline
\end{tabular}

these regions based on apparent protection in DNAse I protection footprinting assays (data not shown). In EMSA, probes Et 4 and Et5 formed only weak and unspecific complexes with $P$. brasiliensis total protein extracts (data not shown), although these regions are rich in predicted transcription elements (Figure 1). We also tested an Et4 variant that had five extra upstream nucleotides. EMSA results were still negative, suggesting that the NIT2 motif predicted in this probe (Figure 1) is not functional.

Overlapping Et12 and Et23 oligonucleotides (nt -255 to 215) formed intense complexes that co-migrated and could be specifically inhibited with 100-fold excess of cold homologous probe (Figure 3A). In cross-competition EMSA experiments, cold Et23 strongly competed with Et12, preventing band shift with as little as 100-fold molar excess. Cold Et12 was a weaker competitor to Et23 binding, since a noticeable decrease in band intensity demanded 500-fold molar excess of Et12 (Figure 3B). The results with $\mathrm{Pb} 18$ extracts presented in Figures $3 \mathrm{~A}$ and $3 \mathrm{~B}$ were similar with extracts from $\mathrm{Pb} 339$ and $\mathrm{Pb} 3$ (data not shown), suggesting that the same protein in each isolate binds to both probes; however affinity for Et23 is possibly higher. Therefore, a DNA binding motif might include the overlapping region from nt -243 to -229 (CTGTTGATCTTTT), for which there are no motifs recognized by the TFsearch computer program (Figure 1). We also designed an Et23 $\Delta$ probe to verify the influence in EMSA of substitution at $-230(\mathrm{C} / \mathrm{A})$. We initially noticed that the Et23 3 band was reproducibly less intense than the Et23 band when assayed with protein extracts from $\mathrm{Pb} 18$ (Figure 3C) and $\mathrm{Pb} 339$ (data not shown), but equally intense with $\mathrm{Pb} 3$ extracts (Figure 3C). In terms of competition with the Et 12 complex, Et23 $\Delta$ was as good a competitor as Et23, while cold Et12 could apparently inhibit band formation with Et $23 \Delta$ more effectively than with Et23 (Figure 3D). Therefore, a C (instead of an A) at position -230 seems to be important for stronger $\mathrm{Pb} 18$ protein binding to Et23.

Figure 3E shows the Et12 and Et23 bands obtained with protein extracts from $\mathrm{Pb} 18, \mathrm{~Pb} 339$ and $\mathrm{Pb} 3$ comparatively in the same radioautogram. It is noticeable that while the bands migrated similarly for each individual isolate, the $\mathrm{Pb} 3$ bands (both Et12 and Et23) migrated faster. It is worth mentioning that we observed similar behavior with Bs8.1 $\Delta$, which was also positive in EMSA with protein extracts from $\mathrm{Pb} 18$ and $\mathrm{Pb} 3$; the shifted band migrated similarly for Pb18 and Pb339, but faster for Pb3 (data not shown). Bs8.1 and Bs8.2 $\Delta$ were only assayed with Pb339 extracts.

Manual search through the PbGP43 promoter region revealed the existence of two CreA-like DNA binding motifs (C/GC/TGGA/GG), whose sequences (CTGGTG 

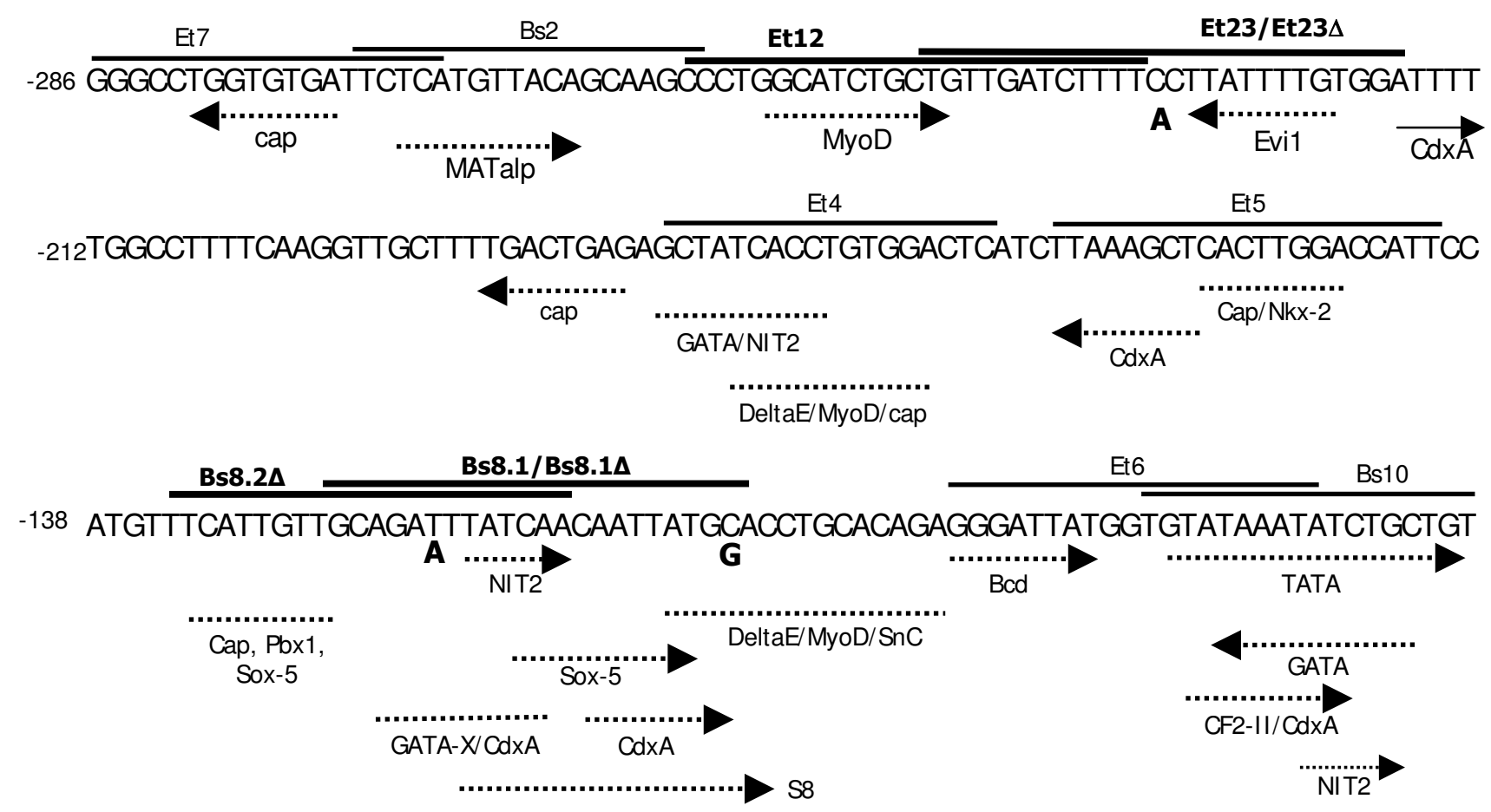

-64 CTCCTCCCTATTTCCCTCCTCCTTCTTTTTACAGATCTTCAAGGTTTTGGTGGTCATAGGCATCATG

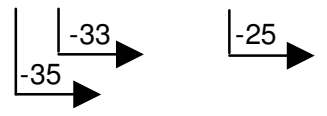

Figure I

PbGP43 5 ' proximal flanking region from $\mathrm{Pb339}$ between $\mathbf{- 2 8 6}$ and $-\mathrm{I}$ showing the positions of oligonucleotides tested by EMSA and putative transcription motifs. ATG start codon is bolded. Oligonucleotides that formed EMSA specific bands are indicated with bolded names. The three substitutions that occur in isolates from PS2 phylogenetic group are indicated at $-104,-130$, and -230 , as well as the three transcription start sites mapped in four different isolates [16]. The positions of some putative transcription motifs detected with the TFsearch program http://www.cbrc.jp/research/db/ TFSEARCH.html are indicated with the correspondent transcription factor. When the $-120(\mathrm{~A})$ and -103 (G) mutations are considered, we point out disappearance of a GATA-X binding site and introduction of a C/EBP motif in Bs8.2 $\Delta$.

and ATGGTG) are observed in the Et6 and Et7 probes (Figure 1, Table 1). CreA is a zinc-finger catabolic repressor in A. nidulans [24] and we tested the probes with Pb339 extracts. We obtained an intense EMSA-positive band with Et7 that could only be removed with a 3,000fold molar excess of cold oligonucleotide, suggesting lack of specificity (data not shown). Et6 formed only a faint band that disappeared upon competition with 250-fold molar excess of cold probe (data not shown).

\section{Analysis of 2,047 bp from the PbGP43 5' flanking region}

In our laboratory, we had long been trying to clone an extended fragment of the 5 intergenic region of the PbGP43 gene using different methods and Pb339 as reference isolate. Recently, we have finally managed to increase sequence information of this region to -2,047 bp (as detailed in Methods), which prompted us to search for length polymorphism in other isolates (Figures 4A). In order to do that, we compared PCR fragments amplified with P4 (forward) and GRN (reverse) primers (Figures 4B) and DNA template from 14 isolates (as coded in [15]). Note that amplicons from $\mathrm{Pb} 2, \mathrm{~Pb} 3, \mathrm{~Pb} 4$ and $\mathrm{Pb} 5$ had similar sizes of around 1,500 bp; amplicons from $\mathrm{Pb} 9$ and $\mathrm{Pb} 17$ were around 3,000 bp, while those from $\mathrm{Pb} 6, \mathrm{~Pb} 8$, $\mathrm{Pb} 10, \mathrm{~Pb} 11, \mathrm{~Pb} 14, \mathrm{~Pb} 16$ and $\mathrm{Pb} 18$ were similar to the original Pb339 fragment migrating at about 2,000 bp.

We next sequenced the Pb3 shorter PCR product; at a similar time frame the $P$. brasiliensis genome from isolates $\mathrm{Pb} 3, \quad \mathrm{~Pb} 18$ and $\mathrm{Pb} 01$ was released http:// www.broad.mit.edu/annotation/genome/

paracoccidioides brasiliensis/MultiHome.html. Therefore, we had a chance to compare our sequences with those analyzed by the Broad Institute and the results are summarized in Figure 4. 
A

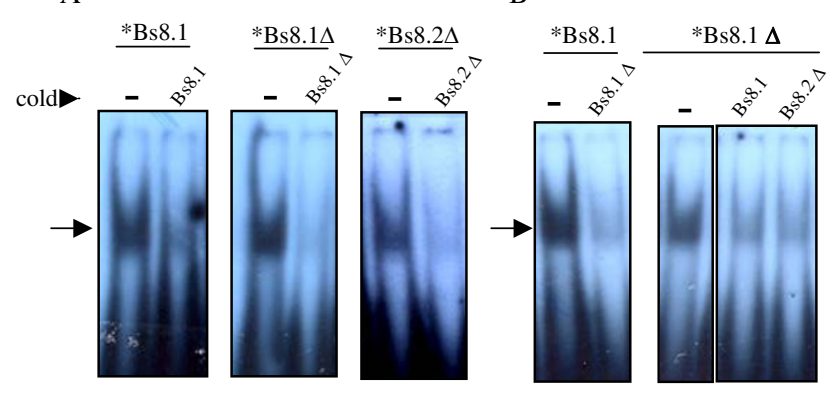

Figure 2

Radioautograms showing EMSA results with Pb339 protein extracts and radio labeled (*) Bs8. I, Bs8.I $\Delta$, and Bs8.2 $\Delta$ probes. In A, specificity of the EMSA bands was suggested by effective competition with $100 \times$ molar excess of cold homologous probe. In $\mathbf{B}$, cross-competition experiments with the indicated probes. Molar excess of cold competitors was $100 \times$. The position of shifted bands is indicated with arrows.

We detected in $\mathrm{Pb} 339$ the presence of three consecutive repetitive regions: $1 \mathrm{a}(-652$ to -156$), 1 \mathrm{~b}(-1159$ to -653$)$ and 1c (-1600 to -1158$)$, which are about 500-bp long (Figure $4 \mathrm{~B}$ ). Two of the regions have initially been detected due to the difficulties to arrange the contigs generated through primer walking sequencing. A middle similar region has only been revealed very recently after further analysis of the data during preparation of this manuscript. The $1 c$ region lacks an initial 58-bp fragment upstream (here referred to as "connector"), which is identical in $1 \mathrm{a}$ and $1 \mathrm{~b}$ (Figure 4C). In Pb339, identities between regions are $89 \%(1 \mathrm{a} \times 1 \mathrm{~b}), 79 \%(1 \mathrm{a} \times 1 \mathrm{c})$ and $90 \%(1 \mathrm{~b} \times 1 \mathrm{c})$. In $\mathrm{Pb} 18$, the structure and sequence of the PbGP43 5' flanking region (2,047 bp) are quite similar to those in Pb339. Sequence identities are also high when comparing the same regions between $\mathrm{Pb} 339$ and $\mathrm{Pb} 18$ : 99\% (1a), 95\% (1b) and 97\% (1c). Pb3 lacks one repetitive region: $1 \mathrm{a}$ in $\mathrm{Pb} 3$ is $96 \%$ identical to $1 \mathrm{a}$ in $\mathrm{Pb} 339$, while $1 \mathrm{c} / \mathrm{a} / \mathrm{b}$ carries nucleotides characteristic of the three regions, however the level of identity is higher with $1 \mathrm{c}$ (94\%) than with $1 \mathrm{~b}(87 \%)$ or $1 \mathrm{a}(78 \%)$. Therefore, when sequence alignments of the repetitive regions from $\mathrm{Pb} 339$, $\mathrm{Pb} 18$ and $\mathrm{Pb} 3$ were compared in a dendrogram, there were two main clusters, one with 1a sequences and another branching into $1 \mathrm{~b}$ and $1 \mathrm{c}$ (and $1 \mathrm{c} / \mathrm{a} / \mathrm{b}$ ) regions (data not shown). Pb3 sequences formed individual branches, in accordance with the phylogenetically distinct nature of this isolate detected with PbGP43 gene and other loci [3,15]. The 442-bp upstream fragment is highly divergent from the repetitive regions, but conserved among isolates (about 99\% identity).

The highly conserved nature of the connector (Figure 4C) drove our attention to a more detailed analysis of its con- tents. We observed that some oligonucleotide sequences occur exclusively in the connectors, while others can be found in other positions of the repetitive regions. In Figure $4 \mathrm{C}$, we boxed six sequences (6-to 8-bp long) that can be found in the positions represented in Figure $4 \mathrm{~B}$ by color-coded arrowheads or bars. Note that the blue oligonucleotide (TTTTCAAG) was invariably found $44 \mathrm{bp}$ upstream of the last base of all repetitive regions. The purple sequence (ATGAAAT) localized 109 bp downstream of the first base of the connector in the three isolates considered; therefore this sequence is not seen in $1 \mathrm{c}$ (or $1 \mathrm{c} / \mathrm{b} / \mathrm{a})$ region. The gray sequence TTGATA in the connector could also be seen in $1 \mathrm{~b}$ region at -883 (Pb339) and -1006 (Pb3). The green ATGTTA oligonucleotide was detected at -1756 (Pb339 and Pb18) and -1261 (Pb3) and at -268 in all isolates. The orange TATAGA was found exclusively in Pb18 and Pb339 at distances of 186 and 184 bp from the start base of $1 \mathrm{a}$ and $1 \mathrm{~b}$ regions. The red-coded corresponding mutated sequence in $\mathrm{Pb} 3$ (TTATTGAT) was also detected 238 bp upstream of the last base in $1 \mathrm{c} / \mathrm{b} / \mathrm{a}$ region; it is not present in $\mathrm{Pb} 18$ or Pb339 connector, but it could be detected at distances varying among 237, 234 and 229 bp upstream of regions $1 \mathrm{a}, 1 \mathrm{~b}$ and $1 \mathrm{c}$ last bases.

The brown CTTATTT initial connector sequence was observed only once in 1a region, 67 bp upstream of the last base in $\mathrm{Pb} 339$ and $\mathrm{Pb} 18$. Although this exact sequence is not observed in the $\mathrm{Pb} 3$ connector, which shows a unique CTTCATT oligonucleotide not found elsewhere, in this isolate CTTATTT has been observed twice in 1 a region, at 67 bp upstream of the last base, and at a polymorphic -372 site. As seen in Figure 4D, CTTATTT is seen in protein-binding oligonucleotide Et23 (Figure 3), near the overlapped fragment with Et12. The Et12/23 fragment in 1 a region is particularly polymorphic when compared to the correspondent sequences in $1 \mathrm{~b}$ and $1 \mathrm{c}$; it is one of the fingerprints of $1 \mathrm{a}$ region. In $1 \mathrm{~b}$ and $1 \mathrm{c}$ regions, this fragment has several putative transcription motifs, as opposed to Et12/Et23 (Figure 1), however we have not tested their protein binding features.

\section{Polymorphism in the 3' UTR of PbGP43}

We compared the 3' UTR of the PbGP43 gene by analyzing 3' RACE products from ten isolates. We used total RNA as template, which has been purified from $P$. brasiliensis yeast phase grown in rich medium (exception: $\mathrm{Pb} 18$, for which the mycelium phase was used). We sequenced the inserts of four to ten clones from each isolate and compared the poly(A) cleavage sites. In our hands, the 3' UTR was conserved intra and inter individuals, i.e., we have not found substitutions in all the 56 fragments sequenced (exception: site 1418 in a single clone from $\mathrm{Pb} 14)$; however there was extensive polymorphism in the poly(A) cleavage site. Out of 56 transcripts we found thirteen close, however different poly(A) sites, which varied in number from one to seven per isolate (Table 2). These sites were 

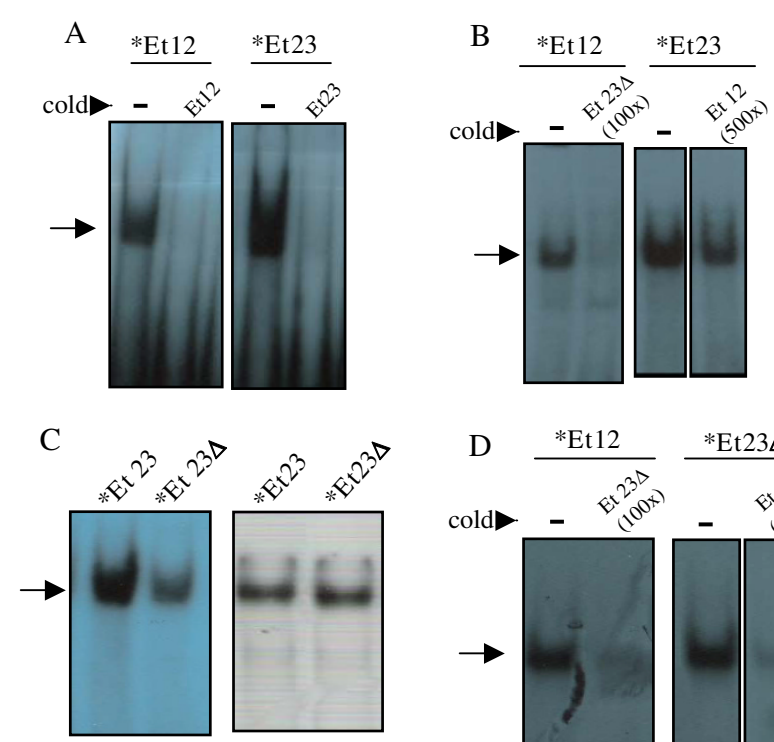

$\mathrm{Pb} 18$
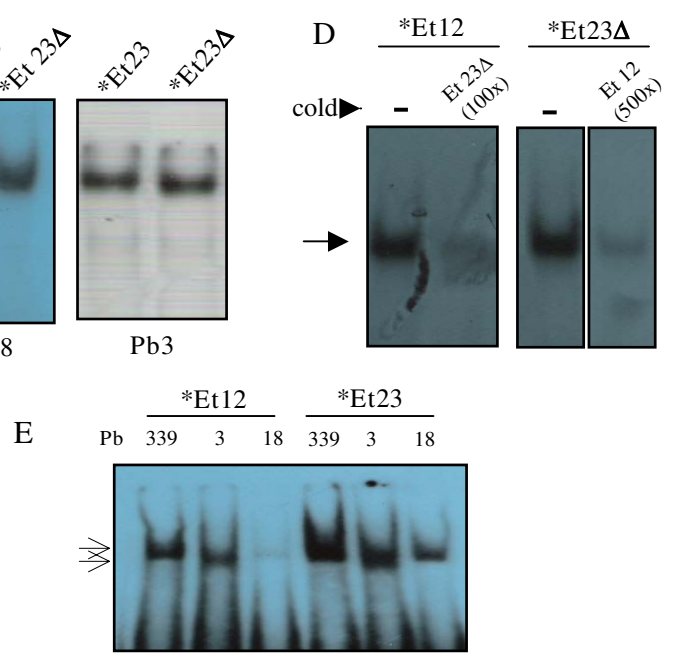

\section{Figure 3}

Radioautograms showing EMSA results with radio labeled (*) Et I 2, Et23, and Et23 $\Delta$ probes. When not specified, protein extracts from $\mathrm{Pb} / 8$ were used. In $\mathbf{A}$, specificity of the EMSA bands was suggested by effective competition with $100 \times$ molar excess of cold homologous probe. In $\mathbf{B}$ and $\mathbf{D}$, cross-competition experiments with the indicated cold probes at $100 \times$ or $500 \times$ molar excess. In C, the intensity of Et23 and Et23 $\Delta$ (mutated in -230 to $A$ ) bands are compared with different protein extracts ( $\mathrm{Pb3}$ or $\mathrm{Pb} / 8$, as indicated). In E, migration of Et 12 and Et23 bands are compared with protein extracts from different isolates (indicated). The position of shifted bands is indicated with arrows.

located between positions 1420 and 1457 (91 to $128 \mathrm{nt}$ from the stop codon, see inset in Table 2) and were mostly pyrimidineA, as precluded to occur in yeasts [25]. The most common sites were 1423 (14 transcripts) and 1434 (10 transcripts).

Total RNA pools (isolated from cells cultivated in rich medium) used as template in the 3' RACE reactions were also analyzed for PbGP43 expression using real time RTPCR. The amount of accumulated transcript varied considerably among isolates (data not shown), from not detected (Pb2, $\mathrm{Pb} 3$, and $\mathrm{Pb} 8)$ to highly abundant (Pb339, followed by Pb10) or low (Pb4, Pb12, Pb14, Pb18). There was no correlation between poly(A) cleavage site and $\mathrm{PbGP43}$ transcript accumulation in these experiments.

\section{Comparative analysis of PbGP43 transcription}

Differences in extracellular gp43 expression among different isolates have been reported in the literature [19] and constantly observed in our laboratory. We have previously suggested that both transcriptional and post-transcriptional mechanisms would contribute to these differences [16]. Presently, we used Pb339, Pb3 and Pb18 in a controlled comparison of transcript accumulation in yeast cells cultivated to logarithmic phase in defined F12/glc medium. At similar cell concentrations for each culture, transcript accumulation was by far higher in Pb339, followed by Pb3 and Pb18 (Table 3). We have observed that differences were not apparent upon modulation with primary nitrogen sources, i.e., PbGP43 transcript from Pb3, $\mathrm{Pb} 18$ and Pb339 were negatively modulated with ammonium sulfate at similar rates [22]. We presently tested two other types of stimuli in cultures growing in F12 medium, specifically, fetal calf serum (FCS) and glucose. As observed in Figure 5, supplementation with 2\% FCS was not able to modulate PbGP43 transcript accumulation in $30 \mathrm{~min}$. On the other hand, an increase in glucose concentration from $0.18 \%$ (present in F12 medium) to $1.5 \%$ for 30 min evoked a decrease in the relative amount of transcripts of about $70 \%$ (2,6-fold for Pb3, 4-fold for Pb18 and 3,5-fold for Pb339). This rate of modulation was similar in Pb339, Pb3 and Pb18, although the initial amount of transcripts varied considerably among them. This kind of negative expression modulation with glucose would be expected for glucanase genes [26].

\section{Discussion}

By using EMSA and a series of probes covering five regions within the upstream 326 bp of the PbGP43 ORF we managed to identify protein binding sequences between nt 134 to -103 and $n t-255$ to -215 . Together, these regions abrogate three substitution sites characteristic of $P$. brasiliensis PS2 isolates: that might not be incidental, since one mutation at -230 seemed to alter binding affinity. By using cross-competition assays with overlapping and mutated probes we suggested binding cores located between nt -125/-112 (TGCAGAA/TTTATCAA) and nt 243/-229 (CTGTTGATCTTTT). Fragment -125/-112 bears putative NIT2 and CdxA binding sites, whereas oligonucleotide from -243 to -229 could be involved in binding to a so far unknown protein. NIT2 modulates transcription of genes that encode enzymes involved in the catabolism of nitrogen sources during starvation [27]. We have recently studied PbGP43 NIT2-binding sites and shown transcription modulation of the PbGP43 with primary nitrogen sources; however the participation of a NIT2 transcription factor binding to the putative motifs at -179 , -117 and -73 was unlikely [22]. The core sequence of 


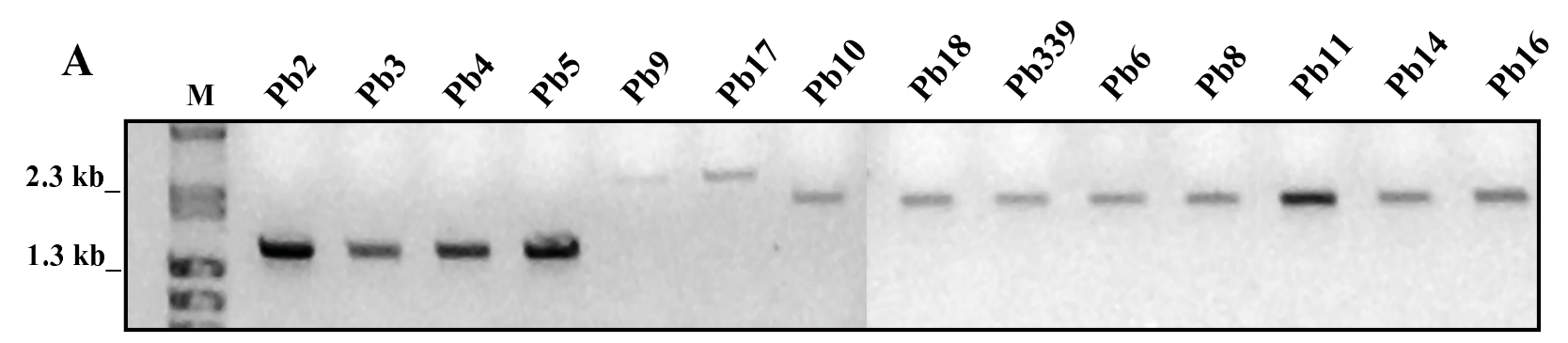

B
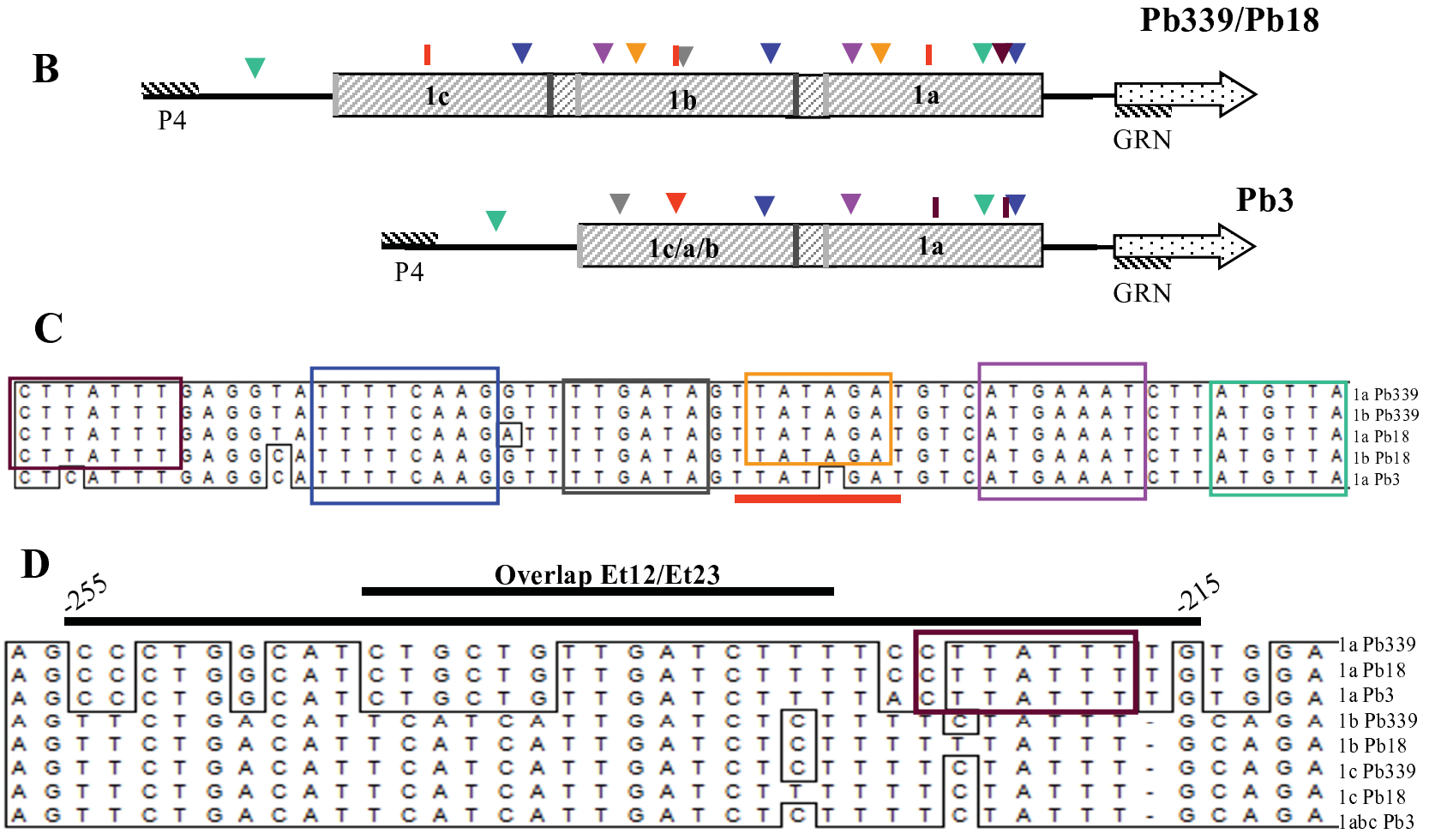

\section{Figure 4}

Analysis of 2,047 bp upstream of the PbGP43 ORF. A, Size comparison of the PbGP43 5 ' flanking region from fourteen P. brasiliensis isolates. Ethidium bromide-stained agarose gel showing the amplicons produced with P4 (forward) and GRN (reverse) primers using genomic DNA from the indicated isolates. M, molecular markers. B, schematic representation of the $\mathrm{PbGP43} 5$ ' flanking region from isolates $\mathrm{Pb} 339 / \mathrm{Pb} / 8$ and $\mathrm{Pb} 3$, where the positions of P4/GRN primers are shown. The repeated regions are boxed and start at the dark gray bar. The lighter-colored box indicates a 58-bp sequence ("connector", shown in C) that is absent in the upstream repeated region Ic and Ic/a/b. The sequences in the color-coded boxes can be found in the sites indicated in $\mathbf{B}$ by the correspondent colored arrow. D, sequence alignment of the Et I $2 / E t 23$ probes ( -255 to -2 I 5 in Ia region) with the correspondent fragments in other regions from $\mathrm{Pb} 3, \mathrm{~Pb} / 8$ and $\mathrm{Pb} 339$, as indicated. The overlap between these probes is indicated, as well as one of the connector sequences (brown) boxed in $\mathbf{C}$.

CdxA-binding element is A/TA/TTA/TA/CTA/G [28], thus allowing for several sequence possibilities. That probably explains why CdxA is one of the most frequently found promoter elements in human genes [29]. Transcription factor CdxA is a homeodomain protein originally described in the early stages of morphogenesis of chicken intestinal tract [30], but its role on regulation of fungal genes has apparently not been addressed. The P. brasiliensis genome does not show any protein with high identities with CdxA, although other homeobox proteins have been annotated. On the other hand, there is a slight similarity of $P$. brasiliensis proteins with Sox-5, whose DNA-binding motif is seen in non-overlapping fragments of the probes covering sequence form -134 and - 103 .

To date, we have not been able to purify and identify the DNA-binding proteins detected here. The probes tested are located close to PbGP43 transcription start sites and we understand from our previous work that the first -480 bp were sufficient to promote basal levels of gene tran- 
scription and also modulation with ammonium sulfate [22]. This fragment contains most of 1a region. When we blasted the overlap -125/-112 (14-mer) and -243/-229 (13-mer) oligonucleotides from EMSA-positive fragments with $P$. brasiliensis upstream intergenic regions http:// www.broad.mit.edu/annotation/genome/

paracoccidioides brasiliensis/MultiHome.html, exact matches were found generally at the 11-mer level in about 20 to 30 genes. Sequence CTGTTGATCTTTT has been found in $P$. brasiliensis homologous genes encoding betahexosaminidase and chitin synthase, but mostly in genes encoding predicted or hypothetical proteins. Concerning the mutated -125/-112 region, we detected identical fragments in the upstream region of one gene encoding betaglucosidase. Therefore, although gp43 is a non-functional $\beta$-1,3-exoglucanase, its gene may have conserved transcription motifs characteristic of those related to carbohydrate metabolism, possibly within the binding sequences identified here. We presently showed negative modulation with glucose of PbGP43 from Pb3, Pb18 and Pb339 at similar rates, but the participation of the binding DNA sequences revealed here in this or other modulations is presently unknown and will have to be addressed using gene reporter experiments.

Basal levels of PbGP43 transcripts varied considerably among isolates (Table 3) corroborating differences observed at extracellular protein levels [19]. By comparing length polymorphism of PbGP43 upstream sequences we observed some correlation with $P$. brasiliensis phylogenetic group PS2 isolates, since DNA from $\mathrm{Pb} 2, \mathrm{~Pb} 3$ and $\mathrm{Pb} 4$ yielded a similarly shorter amplicon of about 1,500 bp. However amplicon from $\mathrm{Pb} 5$ (S1 group [3] and PbGP43 genotype D [17]) was also about this size. P. brasiliensis isolates representative of $\mathrm{S} 1$ group and $\mathrm{PbGP43}$ genotypes $\mathrm{C}, \mathrm{D}$, and $\mathrm{E}$ [17] resulted in amplification of a 2,000 bp-fragment, but exceptions of longer fragments were observed in $\mathrm{Pb} 9$ and $\mathrm{Pb} 17$ (S1, genotype E). It is possible that these isolates bear a forth repetitive region. We noticed that although the accumulated PbGP43 transcripts in Pb339 can be as high as about 1,000-fold that of Pb18 (Table 2), this difference can not be justified by

Table 2: Diversity in the PbGP43 polyadenilation cleavage sites, which are also indicated (bold and italics) in the sequence below.

\begin{tabular}{|c|c|c|c|c|c|c|c|c|c|c|c|c|}
\hline \multirow[t]{2}{*}{ Cleavage sites } & \multicolumn{10}{|c|}{ P. brasiliensis isolates } & \multirow[b]{2}{*}{ clones/site } & \multirow[b]{2}{*}{ base } \\
\hline & I & 2 & 3 & 4 & 5 & 7 & 8 & 10 & 12 & 14 & & \\
\hline 1420 & & & & & & I & & & & & 1 & G \\
\hline 1423 & & 4 & & & 5 & 2 & 1 & 2 & & & 14 & C \\
\hline 1425 & & & & 1 & & & & & & & 1 & $C^{*}$ \\
\hline 1427 & & & 1 & & & & & I & 3 & I & 6 & $\mathrm{~T}$ \\
\hline 1429 & & & 1 & & & & & & & & 1 & $C^{*}$ \\
\hline 1430 & & & & & & I & & I & 1 & & 3 & $\mathrm{~T}$ \\
\hline 1434 & 5 & & & 1 & & & I & & 2 & 1 & 10 & $\mathrm{~T}$ \\
\hline 1439 & I & & & I & & & 2 & & & 1 & 5 & G \\
\hline |44 | & & & & & & I & & I & I & & 3 & C \\
\hline$|45|$ & & & I & I & & & & & I & I & 4 & C \\
\hline 1453 & & & 1 & 1 & & & & & & & 2 & $C^{*}$ \\
\hline 1454 & & & & & 3 & & & & 1 & & 4 & $\mathrm{~T}$ \\
\hline 1457 & & & & & & I & & & I & & 2 & $\mathrm{~T}$ \\
\hline Total amplicons & 6 & 4 & 4 & 5 & 8 & 6 & 4 & 5 & 10 & 4 & 56 & \\
\hline
\end{tabular}

1330tgggactttttacggcttggagcgtaggagaacagctgattatttacgtttacatgtttaacttttattaagaaatggaaaggcttaattgaacacttactaattaattgacattgtttttcactactatccatttgtat | 470 
missing sequences within $-2,047$ to -1 . In addition, even though there is one region missing in $\mathrm{Pb} 3$, accumulated PbGP43 transcripts were only 129-fold less abundant than in $\mathrm{Pb} 339$. Therefore, the relevance of repetitive regions will be better investigated at the level of polymorphisms to explain transcription differences; however the influence of mRNA stability and 3' regulators should not be disregarded. Additionally, differences at the level of RNA processing should be better investigated. Several studies point to intraspecies divergence in gene expression related to mutations in cis-regulatory elements, such as in Cyp $6 g$ 1 (the cytochrome P450 family) from Drosophila melanogaster [31]. Changes in cis-regulatory systems of genes more often underlie the evolution of morphological diversity than do changes in gene number or protein function [32]. Cis-regulatory sequences are more susceptible to mutations; therefore long intergenic regions should accumulate them during evolution. It was surprising, however, to find highly conserved sequences among isolates upstream of the repetitive regions in the 5 ' intergenic region of $\mathrm{PbGP} 43$.

We believe that the quite special arrangements detected in the 5' intergenic region of PbGP43 are not at all incidental, however we can not precise their role at present. In addition, when we blasted the whole Pb339 connector sequence (58 bp) against other dimorphic fungal sequences http://www.broad.mit.edu/annotation/ genome/dimorph_collab.1/MultiHome.html we realized that fragments of fifteen to thirteen bp or even longer (17 bp) are conserved in the 5' upstream regions from other genes, although mostly from predicted or hypothetical proteins. This specific search resulted in, for e.g., six matches with sequences from $\mathrm{Pb} 18$, three from Pb3, thirty-three from Pb01 and 13 from $H$. capsulatum. The sequence TTCAAGGTTTTGATAGTTATAG, including the blue and gray fragments (Figure 4C) was detected in the uracil DNA glycosidase superfamily from $H$. capsulatum

\begin{tabular}{|c|c|c|c|c|}
\hline Isolate & Samples & TA & $N^{\circ}$ of cells $/ m L$ & $\mathbf{N}^{\circ}$ of days \\
\hline \multirow[t]{3}{*}{ Pb339 } & Expl & $3860 \pm 5 I, 5$ & $9,2 \times 10^{6}$ & 4 \\
\hline & Exp2 & $4443 \pm 25,6$ & $\mathrm{I}, \mathrm{I} \times 10^{7}$ & 4 \\
\hline & Exp3 & $10106 \pm 108$ & $1,6 \times 10^{7}$ & 4 \\
\hline \multirow[t]{3}{*}{$\mathrm{Pb} 3$} & Expl & $41,6 \pm 3,9$ & $8,9 \times 10^{6}$ & 4 \\
\hline & Exp2 & $\mathbf{5 5 , 5} \pm 4,3$ & $1 \times 10^{7}$ & 4 \\
\hline & Exp3 & $5 \mathrm{I}, 66 \pm 4,8$ & $1,1 \times 10^{7}$ & 4 \\
\hline \multirow[t]{3}{*}{$\mathrm{PbI} 8$} & Expl & $\mathbf{7 , 4} \pm 0,8$ & $1,4 \times 10^{7}$ & 6 \\
\hline & Exp2 & $4,1 \pm 0,5$ & $1 \times 10^{7}$ & 6 \\
\hline & Exp3 & $6,95 \pm 0,5$ & $1,2 \times 10^{7}$ & 6 \\
\hline
\end{tabular}

TA, relative number of transcript copies when compared with $\alpha$ tubulin.

Culture densities and ages are indicated.
H143; TATTTGAGGTATTTTCAA, including the brown and blue fragments (Figure 4C) was seen upstream of the acid phosphatase gene in the same isolate and part of it (ATTTGAGGTATTTT) was also found upstream of a reduced viability upon starvation protein in Pb18. Another fragment containing the red and pink sequences (Figure 4C) (TTATAGATGTCATGAAAT) is upstream of the MAP kinase gene in $H$. capsulatum $\mathrm{H} 88$.

Isolate Pb01 probably belongs to a different Paracoccidioides species whose proposed name is P. lutzii $[33,34]$. In this isolate, the gene homologue to PbGP43 shows extensive polymorphism in the ORF, bearing only $80 \%$ identity with gp43 from Pb18. The predicted protein (PAAG 05770.1) does not have any $N$-glycosylation site, mutated NEP, or conserved P10, therefore it is a potentially active glucanase. The 5' intergenic region is reduced to about $990 \mathrm{bp}$, when the first exon from a gene homologous to that encoding succinate-semialdehyde dehydrogenase starts. In this fragment, we could observe one region that aligns with $1 \mathrm{a}, 1 \mathrm{~b}$ and $1 \mathrm{c}$ regions, however with many divergences and two long gaps. Therefore, the transcripts are probably regulated differently, but there are no experimental data available to confirm that.

Protein binding probes were positive in EMSA carried out with total protein extracts from Pb339, Pb18 and Pb3; however EMSA bands migrated generally faster with $\mathrm{Pb} 3$ extracts and that could be related to the genetic differences found in isolates belonging to PS2. Interestingly, we observed that probes containing an AP-1 recognition sequence or heat shock elements within the shared 5' intergenic region between $\mathrm{Pb} L O N$ and $\mathrm{PbMDJ} 1$ formed EMSA bands that migrated consistently faster with protein extracts from Pb3 [23]. By comparing Pb3 and Pb18 AP-1 and HSF genome sequences, however, we observed that they are quite conserved; therefore polymorphism could not explain migration differences, which might be due to post-translational modifications in the translation factors or even binding to distinct proteins in different isolates.

One of the processing steps of pre-messenger RNA before export to the cytoplasm for translation involves endonucleolytic 3' cleavage for definition of the UTR and addition of the poly(A) tail. In higher eukaryotes, the choice of poly(A) sites involves, among others, a poly(A) signal (PAS) hexamer AAUAAA (or variants), localized 10 to 30 nt upstream of the poly $(\mathrm{A})$ site, and $U(\mathrm{U} / \mathrm{G})$-rich region (DSE) that lays 20 to $40 \mathrm{nt}$ downstream of the poly(A) site $[27,35]$. The PAS hexamer binds to a poly(A) specific factor, while DSE bears binding sites to a cleavage stimulating factor that directs polyadenylation. In our studies we found multiple poly(A) cleavage sites between positions 1,420 and 1,457 of the PbGP43 3 ' UTR. There is an AAGAAA sequence 21 nt upstream of position 1,420, 

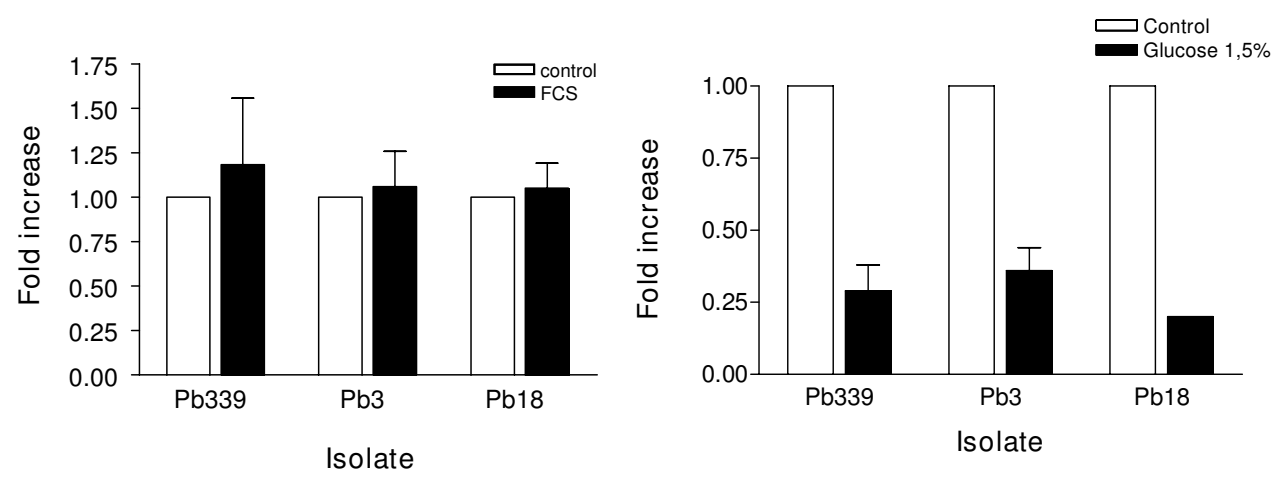

\section{Figure 5}

Accumulation of PbGP43 transcript after $\mathbf{3 0}$ min of stimulus of $P$. brasiliensis yeast cells with glucose or fetal calf serum (FCS). Real time RT-PCR experiments showing the relative variation of PbGP43 transcript accumulation in Pb339, $\mathrm{Pb} / 8$ and $\mathrm{Pb} 3$ cells stimulated with A, $2 \%$ FCS or B, I,5\% glucose. Control experiments were attributed value I.0. The $\alpha$-tubulin gene was used as standard.

which is a potential PAS, or positioning element as defined in yeast [25]. According to a survey on PAS hexamers in 13,942 human and 11,150 mouse genes [36], AAGAAA was the fifth most frequent PAS hexamer found, at a frequency of $2.99 \%$ in humans and $2.15 \%$ in mice. In the same study, the authors observed that heterogeneity of poly(A) cleavage sites occurred most frequently within a range of $24 \mathrm{bp}$. Therefore, they have defined poly(A) sites up to 24-bp long. They also noticed that the occurrence of multiple potentially alternative poly(A) sites in $54 \%$ of human genes. We analyzed 56 3' UTR sequences from a single gene (PbGP43) in ten isolates of $P$. brasiliensis and observed that within a range of $37 \mathrm{bp}$ there were two main clusters $(1,420$ to 1,441 and 1,451 to 1,457$)$ of multiple cleavage sites separated by one to five bp (Table 2). They are separated by ten bp and we could speculate that they constitute two alternative poly(A) sites. Only $21 \%$ of the sequences (from six isolates) had cleavage sites in the second cluster. It is worth mentioning that the sequence downstream of the $3^{\prime}$-most cleavage site is U/UG-rich, as in mammal DSE, although this element has not been described in yeasts [25]. Differences in the PAS hexamer could result in diversity of cleavage sites. Our analysis showed conserved 3' UTR in the PbGP43, therefore polymorphism in poly(A) cleavage site has a different origin. In yeasts, the role of close but alternative poly(A) site is unknown [25] and in P. brasiliensis this subject has originally been studied here. Comparison of 326 bp of PbGP43 3' intergenic region from Pb339 (U2616.2) with genome sequences http://www.broad.mit.edu/annotation/genome/paracoccidioides brasiliensis/Multi-

Home.html shows substitutions in positions 1,364, 1,385, 1,446, 1,563, 1,594 for Pb3 and Pb18, which have not been detected in the present work.

\section{Conclusions}

We have undertaken extensive studies on polymorphisms in the $5^{\prime}$ and $3^{\prime}$ intergenic regions of the PbGP43 gene from Paracoccidioides brasiliensis. We have characterized 2,047 bp of intergenic region and described a peculiar type of sequence structure with repetitive fragments. Two promoter regions containing polymorphic nucleotides were able to bind protein. We have detected differences that might guide future efforts to understand transcriptional differences of PbGP43 among isolates.

\section{Methods}

\section{Fungal isolates and growth conditions}

P. brasiliensis clinical isolates $\mathrm{Pb} 18, \mathrm{~Pb} 3$ (originally 608) and Pb339 (B-339) were the focus of this work. Genetic material from $\mathrm{Pb} 2$ (originally 1925), $\mathrm{Pb} 4$ (originally 1014), Pb5 (originally AP), Pb9 (originally 924), Pb10 (originally Peru), Pb11 (originally Mg5), Pb12 (originally Argentina), Pb14 (originally 470), Pb16 (originally solo) and $\mathrm{Pb} 17$ (originally tatu) were also analyzed for polymorphism in the 3' UTR and poly(A) cleavage site and/or length polymorphism of the 5 ' intergenic region. Details about the origin of these isolates, as well as their genetic groups according with the PbGP43 phylogeny and multilocus studies can be found elsewhere $[3,15]$. The isolates were maintained in the yeast phase in slants of modified YPD medium (mYPD, 0.5\% yeast extract, $0.5 \%$ casein peptone, $1.5 \%$ glucose, $\mathrm{pH} 6.3$ ) either at $36^{\circ} \mathrm{C}$, with subculturing every 20 days, or at $4^{\circ} \mathrm{C}$ for some months.

\section{Extraction of total DNA, RNA and preparation of total protein extracts}

Total protein extracts used in DNA binding assays were obtained as detailed previously [23], using $P$. brasiliensis yeast cells from $\mathrm{Pb} 18, \mathrm{~Pb} 3$ and $\mathrm{Pb} 339$ incubated at $36^{\circ} \mathrm{C}$ 
in mYPD with shaking (120 r.p.m.) for four to five days. Total DNA-free RNA was isolated from Pb18, Pb3 and Pb339 yeast cells using approximately $0.1 \mathrm{ml}$ of wet pellets and the TRizol reagent (Invitrogen), as previously described [22]. For RNA extraction followed by real time RT-PCR, fungal cells were cultivated at $36^{\circ} \mathrm{C}$ with shaking in F12 medium (Gibco) supplemented with 1.5\% glucose (F12/glc). Transcription modulation with fetal bovine serum (FBS) was verified by stimulating log-phase yeast cells growing in F12/glc with 2\% FBS for 30 min. For transcription modulation with glucose, log-phase cultures in F12 medium (that has $0.18 \%$ glucose in its formulation) were supplemented with glucose to $1.5 \%$ final concentration. Total RNA-free DNA was purified from mechanically disrupted $P$. brasiliensis yeast cells cultivated in mYPD $[12,15]$.

\section{Electrophoretic mobility shift assays (EMSA)}

We followed EMSA protocols described by Tosco et al. [37] with annealed sense (Table 1) and anti-sense oligonucleotides, as detailed in our previous reports $[22,23]$. Briefly, double-stranded oligonucleotides (60,000 c.p.m) were radio labeled with $\left[\gamma^{32} \mathrm{P}\right]$ dATP $(10 \mathrm{mCi} / \mathrm{ml}$, Amersham) and incubated $\left(15 \mathrm{~min}\right.$ at $\left.37^{\circ} \mathrm{C}\right)$ with an ice-cold solution containing $10 \mu \mathrm{g}$ of total protein extract from $P$. brasiliensis, $1.5 \mu \mathrm{L}$ of poly dI-dC $(1.25 \mathrm{mg} / \mathrm{mL}), 1.5 \mu \mathrm{L}$ of BSA $(10 \mathrm{mg} / \mathrm{mL})$ and $3 \mu \mathrm{L}$ of a solution containing 125 $\mathrm{mM}$ Hepes, pH 7.5, $5 \mathrm{mM}$ EDTA and 50\% glycerol in a total reaction volume of $12 \mu \mathrm{l}$. Competition assays were incubated in the presence of molar excess of cold oligonucleotides. The reactions were separated in $6 \%$ non-denaturing polyacrylamide gels (37.5:1 acrilamide/bisacrilamide) run in $0.5 \times$ TBE buffer either for $45 \mathrm{~min}$ at $100 \mathrm{~V}$ in a mini-Protean II apparatus (BioRad), or for one hour at $20 \mathrm{~mA}$ in $14 \times 12 \mathrm{~cm}$ gels. The gels were dried and exposed to an X-Omat (Kodak) film at $-70^{\circ} \mathrm{C}$.

\section{Cloning an extended fragment of the 5 ' intergenic region of PbGP43}

We developed a strategy to clone an extended fragment of the PbGP43 5' intergenic region using PCR and a combination of primers from i) an internal 5 region of the PbGP43 ORF (PCRia, reverse primer, 5'-GCGAGAACACAGCTGGCAAGAGCCAGGTTAAGAG-3'); ii) conserved ORF regions from the 5 ' neighboring gene of fungal $\beta$-1,3-glucanases homologous to PbGP43 (forward consensus primers). By the time we used that strategy there was publicly available genome information from Aspergillus fumigatus http://www.tigr.org/tdb/e2k1/afu1/, A. nidulans and $A$. terreus http://www.broad.mit.edu/ node/568. We also counted on $H$. capsulatum and B. dermatitidis preliminary sequencing data kindly supplied by Dr. William E. Goldman, presently at the Duke University Medical Center. We found in H. capsulatum, A. terreus and A. nidulans a homologous GPI-anchored protein ORF lying $5.5 \mathrm{~kb}$ to $9.2 \mathrm{~kb}$ away from the $\beta$-1,3-glucanase gene. Three primers were designed from homologous DNA internal regions from that ORF. A series of PCR reactions were carried out at different annealing temperatures and primer combinations using a Long PCR Enzyme kit (Fermentas). Primers were also tested individually to control for unspecific bands. The PCR reactions were visualized in ethidium bromide gels, then Southern-blotted and hybridized with a probe covering 110 bp of the PbGP43 5' proximal flanking region. A 1.8-kb fragment hybridized more strongly than others with the radioactive probe, and although it was the product of PCRia primer alone, it was cloned in pGEM-T vector and sequenced. Sequence information and a series of subsequent PCR, using selected primers from the newly sequenced region paired with ORF primers, showed that we managed to fortuitously clone an extended part of the 5 ' intergenic region to a total of 2,047 bp (updated U26160.2). For subsequent length polymorphism studies of this region, we compared amplicons obtained with internal PbGP43 reverse primer (GRN, 5'-GAGGATCCCATGATGCCTATGCC-3') and forward P4 primer (5'-CAGCAGCATATTTGATTTCCT-3'), as shown in Results.

\section{3' RACE RT-PCR}

We used 3' RACE RT-PCR to obtain individual PbGP43 transcripts and further compare their sequences and poly(A) sites. The reactions were assayed using the ThermoScript RT-PCR System (Gibco) and total DNA-free RNA from 10 P. brasiliensis isolates. Total cDNA was elongated using a standard oligo-dT primer (5'GACTCGAGTCGACATCGT $\left._{17}-3^{\prime}\right)$. The second strand and DNA amplifications were obtained with a forward PbGP43 internal primer located at the 3' end (5'-CGATGCTCGCTTCCTCAT-3') and reverse corresponding to oligo-dT without the T-tail (5'-GACTCGAGTCGACATCG$\left.3^{\prime}\right)$. PCR reactions $(100 \mu \mathrm{L})$ were carried out in $50 \mathrm{mM}$ $\mathrm{KCl}, 1.5 \mathrm{mM} \mathrm{MgCl}_{2}, 10 \mathrm{mM}$ Tris-HCl, $\mathrm{pH} 9.0,50 \mu \mathrm{M}$ of each dNTP, $1 \mu \mathrm{M}$ of each primer and $5 \mathrm{U}$ Taq polimerase (Amersham). Cycling involved $5 \mathrm{~min}$ at $95^{\circ} \mathrm{C}$, followed by 30 cycles at $95^{\circ} \mathrm{C}(1 \mathrm{~min}), 55^{\circ} \mathrm{C}(1 \mathrm{~min})$ and $72^{\circ} \mathrm{C}(3$ $\mathrm{min}$, then $10 \mathrm{~min})$. The amplified products were cloned into a pGEM-T vector (Promega). A series of transformed bacterial clones were selected for plasmid purification and insert sequence analysis.

\section{Quantitative real time RT-PCR}

Quantitative real time RT-PCR was carried out using the Syber Green detection system (Applied Biosystems), following the manufacturer's instructions and details provided in our previous report [22]. The PbGP43 ORF primers used in the reactions were 5'-TCGTGATATAGACAGCACCGTTG-3' (forward) and 5'- AAGACTTGGTTGTGGTATGTGTCG-3' (reverse). P. brasiliensis $\alpha$-tubulin gene was used as calibrator with primers 5'-CGGCTAAT- 
GGAAAATACATGGC-3' (forward) and 5'-GTCTTGGCCTTGAGAGATGCAA-3' (reverse). Cycling was performed in an ABI Prism 7000 Sequence Detection System (Perkin-Elmer Applied Biosystem, USA) starting with one cycle of $50^{\circ} \mathrm{C}(2 \mathrm{~min})$ and $95^{\circ} \mathrm{C}(1 \mathrm{~min})$, followed by 40 cycles at $95^{\circ} \mathrm{C}(15 \mathrm{sec})$ and $60^{\circ} \mathrm{C}(1 \mathrm{~min})$, and an additional cycle of $95^{\circ} \mathrm{C}(15 \mathrm{sec}), 60^{\circ} \mathrm{C}(20 \mathrm{sec})$ and $95^{\circ} \mathrm{C}(15$ $\mathrm{sec}$ ) for determination of the dissociation curve. Negative controls did not contain DNA or RNA. Reactions were run in triplicates and in parallel with the $\alpha$-tubulin calibrator. We built a standard curve for each probe by assaying increasing amounts of theoretical copy numbers of each gene obtained with serial dilutions of $P$. brasiliensis genomic DNA, as described [38]. The final data were presented as the mean $\pm \mathrm{SD}$.

\section{Sequence analysis}

Nucleotide sequencing was carried out in the facilities of the Center of Human Genome at the São Paulo University (USP). Manual sequencing of 3' RACE products was carried out as described [15]. Sequences were analyzed using the EditSeq, SeqMan and MegAlign programs of the Lasergene System (DNAstar Inc.). Putative transcription motifs were deduced by the TFSearch program http:// www.cbrc.jp/research/db/TFSEARCH.html.

\section{Authors' contributions}

AAR participated in the preparation of the manuscript, designed and performed EMSA experiments with the Et probes, cloned, assembled and analyzed the expanded 5' flanking region, performed RT-PCR experiments; FVM designed and performed EMSA experiments with Bs probes, sequenced and analyzed polymorphisms of the $3^{\prime}$ flanking region; RP gained funds to develop the projects, wrote the manuscript, analyzed data and supervised the development of the Ph.D. projects from AAR and FVM, whose partial data are contained in this manuscript. All authors read and approved the final manuscript.

\section{Acknowledgements}

We thank Dr. Marjorie Marini for discussions. This work was supported by FAPESP grants and scholarships to AA Rocha and FV Morais. RP is recipient of a CNPq productivity fellowship.

\section{References}

I. Restrepo A, McEwen JG, Castaneda E: The habitat of Paracoccidioides brasiliensis: how far from solving the riddle? Medical Mycology 200I, 39:233-24I.

2. Almeida AJ, Carmona JA, Cunha C, Carvalho A, Rappleye CA, Goldman WE, et al.: Towards a molecular genetic system for the pathogenic fungus Paracoccidioides brasiliensis. Fungal Genet Biol 2007, 44: 1387-1398.

3. Matute DR, McEwen JG, Puccia R, Montes BA, San G Blas, Bagagli E, et al: Cryptic speciation and recombination in the fungus Paracoccidioides brasiliensis as revealed by gene genealogies. Mol Biol Evol 2006, 23:65-73.

4. Puccia R, Schenkman S, Gorin PA, Travassos LR: Exocellular components of Paracoccidioides brasiliensis: identification of a specific antigen. Infect Immun 1986, 53:199-206.
5. Travassos LR, Rodrigues EG, Iwai LK, Taborda CP: Attempts at a peptide vaccine against paracoccidioidomycosis, adjuvant to chemotherapy. Mycopathologia 2008, 165:341-352.

6. Puccia R, Travassos LR: 43-kilodalton glycoprotein from Paracoccidioides brasiliensis: immunochemical reactions with sera from patients with paracoccidioidomycosis, histoplasmosis, or Jorge Lobo's disease. J Clin Microbiol 1991, 29:1610-1615.

7. Camargo ZP: Serology of paracoccidioidomycosis. Mycopathologia 2008, 165:289-302.

8. Buissa-Filho R, Puccia R, Marques AF, Pinto FA, Munoz JE, Nosanchuk JD, et al:: The monoclonal antibody against the major diagnostic antigen of Paracoccidioides brasiliensis mediates immune protection in infected BALB/c mice challenged intratracheally with the fungus. Infect Immun 2008, 76:332I-3328.

9. Marques AF, da Silva MB, Juliano MA, Munhoz JE, Travassos LR, Taborda CP: Additive effect of PIO immunization and chemotherapy in anergic mice challenged intratracheally with virulent yeasts of Paracoccidioides brasiliensis. Microbes Infect 2008, 10:125I-I 258.

10. Gesztesi JL, Puccia R, Travassos LR, Vicentini AP, de Moraes JZ, Franco MF, et al: Monoclonal antibodies against the 43,000 Da glycoprotein from Paracoccidioides brasiliensis modulate laminin-mediated fungal adhesion to epithelial cells and pathogenesis. Hybridoma 1996, 15:4I5-422.

II. Mendes-Giannini MJ, Andreotti PF, Vincenzi LR, da Silva JL, Lenzi HL, Benard G, et al.: Binding of extracellular matrix proteins to Paracoccidioides brasiliensis. Microbes Infect 2006, 8: 1550-I559.

12. Cisalpino PS, Puccia R, Yamauchi LM, Cano MI, da Silveira JF, Travassos LR: Cloning, characterization, and epitope expression of the major diagnostic antigen of Paracoccidioides brasiliensis. J Biol Chem 1996, 27 I:4553-4560.

13. Sorokin AV, Kim ER, Ovchinnikov LP: Nucleocytoplasmic transport of proteins. Biochemistry (Mosc) 2007, 72:1439-1457.

14. Feitosa LS, Cisalpino PS, dos Santos MR, Mortara RA, Barros TF, Morais FV, et al.: Chromosomal polymorphism, syntenic relationships, and ploidy in the pathogenic fungus Paracoccidioides brasiliensis. Fungal Genet Biol 2003, 39:60-69.

15. Morais FV, Barros TF, Fukada MK, Cisalpino PS, Puccia R: Polymorphism in the gene coding for the immunodominant antigen gp43 from the pathogenic fungus Paracoccidioides brasiliensis. J Clin Microbiol 2000, 38:3960-3966.

16. Carvalho KC, Ganiko L, Batista WL, Morais FV, Marques ER, Goldman GH, et al.: Virulence of Paracoccidioides brasiliensis and gp43 expression in isolates bearing known PbGP43 genotype. Microbes Infect 2005, 7:55-65.

17. Puccia R, McEwen JG, Cisalpino PS: Diversity in Paracoccidioides brasiliensis. The PbGP43 gene as a genetic marker. Mycopathologia 2008, 165:275-287.

18. Camargo Z, Unterkircher C, Campoy SP, Travassos LR: Production of Paracoccidioides brasiliensis exoantigens for immunodiffusion tests. J Clin Microbiol I988, 26:2I47-2I5I.

19. Moura-Campos MC, Gesztesi JL, Vincentini AP, Lopes JD, Camargo ZP: Expression and isoforms of gp43 in different strains of Paracoccidioides brasiliensis. J Med Vet Mycol 1995, 33:223-227.

20. Stambuk BU, Puccia R, de Almeida ML, Travassos LR, Schenkman S: Secretion of the $43 \mathrm{kDa}$ glycoprotein antigen by Paracoccidioides brasiliensis. J Med Vet Mycol 1988, 26:367-373.

21. Puccia R, Carmona AK, Gesztesi JL, Juliano L, Travassos LR: Exocellular proteolytic activity of Paracoccidioides brasiliensis: cleavage of components associated with the basement membrane. Med Mycol 1998, 36:345-348.

22. Rocha AA, Malavazi I, Goldman GH, Puccia R: Transcription regulation of the Pbgp43 gene by nitrogen in the human pathogen Paracoccidioides brasiliensis. Fungal Genet Biol 2009, 46:85-93.

23. Batista WL, Barros TF, Goldman GH, Morais FV, Puccia R: Identification of transcription elements in the $5^{\prime}$ intergenic region shared by LON and MDJI heat shock genes from the human pathogen Paracoccidioides brasiliensis. Evaluation of gene expression. Fungal Genet Biol 2007, 44:347-356.

24. Panozzo C, Cornillot E, Felenbok B: The CreA repressor is the sole DNA-binding protein responsible for carbon catabolite repression of the alcA gene in Aspergillus nidulans via its binding to a couple of specific sites. J Biol Chem 1998, 273:6367-6372.

25. Zhao J, Hyman L, Moore C: Formation of mRNA 3' ends in eukaryotes: mechanism, regulation, and interrelationships 
with other steps in mRNA synthesis. Microbiol Mol Biol Rev 1999, 63:405-445.

26. Martin K, McDougall BM, Mcllroy S, Chen J, Seviour RJ: Biochemistry and molecular biology of exocellular fungal beta- $(1,3)-$ and beta-(I,6)-glucanases. FEMS Microbiol Rev 2007, 31:168-192.

27. Marzluf GA: Genetic regulation of nitrogen metabolism in the fungi. Microbiology and Molecular Biology Reviews 1997, 61:17-32.

28. Margalit Y, Yarus S, Shapira E, Gruenbaum Y, Fainsod A: Isolation and characterization of target sequences of the chicken Cdxa homeobox gene. Nucleic Acids Research 1993, 21:4915-4922.

29. Bajic VB, Brent MR, Brown RH, Frankish A, Harrow J, Ohler U, et al:: Performance assessment of promoter predictions on ENCODE regions in the EGASP experiment. Genome Biology 2006, 7(SuppI I):S3.

30. Frumkin A, Pillemer G, Haffner R, Tarcic N, Gruenbaum Y, Fainsod $A$ : A role for CdxA in gut closure and intestinal epithelia differentiation. Development 1994, 1 20:253-263.

31. Daborn PJ, Yen JL, Bogwitz MR, Le Goff G, Feil E, Jeffers S, et al.: A single p450 allele associated with insecticide resistance in Drosophila. Science 2002, 297:2253-2256.

32. Carroll $S B$ : Endless forms: the evolution of gene regulation and morphological diversity. Cell 2000, 101:577-580.

33. Carrero LL, Nino-Vega G, Teixeira MM, Carvalho MJ, Soares CM, Pereira M, et al:: New Paracoccidioides brasiliensis isolate reveals unexpected genomic variability in this human pathogen. Fungal Genet Biol 2008, 45:605-6I2.

34. Teixeira MM, Theodoro RC, de Carvalho MJ, Fernandes L, Paes HC, Hahn RC, et al: Phylogenetic analysis reveals a high level of speciation in the Paracoccidioides genus. Mol Phylogenet Evol 2009, 52:273-283.

35. Mandel CR, Bai Y, Tong L: Protein factors in pre-mRNA 3'-end processing. Cell Mol Life Sci 2008, 65:1099-II 22.

36. Tian $B, H u J$, Zhang $H$, Lutz CS: A large-scale analysis of mRNA polyadenylation of human and mouse genes. Nucleic Acids Res 2005, 33:20I-2I2

37. Tosco A, Gargano S, Kobayashi GS, Maresca B: An API element is involved in transcriptional regulation of Delta(9)-desaturase gene of Histoplasma capsulatum. Biochemical and Biophysical Research Communications 1997, 230:457-46I.

38. Semighini CP, de Camargo ZP, Puccia R, Goldman MH, Goldman GH: Molecular identification of Paracoccidioides brasiliensis by 5 nuclease assay. Diagn Microbiol Infect Dis 2002, 44:383-386.
Publish with Bio Med Central and every scientist can read your work free of charge

"BioMed Central will be the most significant development for disseminating the results of biomedical research in our lifetime. "

Sir Paul Nurse, Cancer Research UK

Your research papers will be:

- available free of charge to the entire biomedical community

- peer reviewed and published immediately upon acceptance

- cited in PubMed and archived on PubMed Central

- yours - you keep the copyright

Submit your manuscript here:

http://www.biomedcentral.com/info/publishing_adv.asp
BioMedcentral 